\title{
APUNTES VETEROTESTAMENTARIOS PARA UNA TEOLOGÍA SISTEMÁTICA DE LA EXPIACIÓN
}

Fecha de recepción: 20 de noviembre de 2020

Fecha de aceptación: 05 de enero de 2021

RESUMEN: Para ayudar a clarificar el concepto de «expiación» este artículo busca rastrear sus principales elementos en la teología veterotestamentaria. Tras una panorámica de los usos del término en el Antiguo Testamento nos centramos en la expiación en el documento sacerdotal (donde es entendida en el marco de los sacrificios rituales) y después en su dimensión intercesora, con un especial detenimiento en la mediación del siervo de Yahveh del Deuteroisaías. Concluimos que la expiación es un proceso relacional en el que Dios borra el mal del ser humano y posibilita la reconciliación (con la participación de la persona y normalmente de un mediador).

PALABRAS CLAVE: expiación; teología bíblica; soteriología; mediador; siervo de Yahveh.

\section{Old Testament's Notes for a Systematic Theology of Expiation}

ABSTRACT: To help to clarify the concept of «expiation» this article seeks to trace its main elements in the Old Testament's theology. After an overview of the uses of the term in the Old Testament we focus on the expiation in the priestly document (where it is understood in the context of ritual sacrifices) and then on its inter-

Universidad Pontificia Comillas: mmedina@comillas.edu;

ORCID: https://orcid.org/0000-0002-0577-4262 
cessory dimension, with a special focus on the mediation of the Deuteroisaiah's servant of Yahweh. We conclude that expiation is a relational process in which God removes evil from the human being and enables reconciliation (with the person's participation and normally with a mediator).

KEY WORDS: expiation; atonement; biblical theology; soteriology; mediator; servant of Yahweh.

El objetivo de este artículo es profundizar en la concepción veterotestamentaria de la expiación para extraer conclusiones que nos permitan encaminarnos hacia una definición del término y establecer los elementos que, desde la comprensión bíblica de la cuestión, conformen el marco para un futuro acercamiento a la misma desde la teología sistemática.

Comenzaremos con una visión panorámica y sintética de la expiación en el Antiguo Testamento. Este tema es muy extenso y no se reduce solamente a una palabra, sino que se expresa con diferentes términos, metáforas y narraciones. A ello se suma la compleja cuestión de la datación de los textos, ya que la acepción de un mismo término puede variar según la época y el contexto histórico.

Dada la extensión y el objetivo del presente ensayo, nuestra perspectiva será solamente sincrónica y, además, se centrará en dos pasajes trascendentales para nuestro tema. Nos referimos, en primer lugar, al documento sacerdotal (especialmente Lv 1-7 y Lv 16), donde la expiación es comprendida en el marco de los sacrificios rituales y que emplea la raíz kipper como término técnico para designarla; y, en segundo lugar, a la mediación del Siervo de Yahveh del Deuteroisaías (Is 52,13-53,12), un contexto más existencial que sitúa la expiación en el marco de su dimensión intercesora y que se trata de un texto único en el A. T. por el valor salvífico que se otorga al sufrimiento. Para ello nos serviremos de las investigaciones de especialistas en el campo de la exégesis y la teología bíblicas.

La clarificación conceptual de este término en concreto nos parece especialmente valiosa debido a la confusión que presenta no sólo el concepto en sí, como ya hemos apuntado, sino también el término inglés para referirse a él: atonement. Esta palabra designa tanto el proceso completo de la redención, haciendo hincapié en la reconciliación que se consigue con ella (aunque no es exactamente sinónimo de reconciliation), como el medio sacrificial por el que se lleva a cabo, entendiendo por tal 
medio la expiación en sentido estricto ${ }^{1}$. El inglés también posee el término expiation, pero es mucho menos frecuente que atonement, incluso en la literatura científica. En otros idiomas (como el francés y el castellano) no tenemos este problema, pero deberemos mantener cierta cautela al manejar estudios realizados en inglés ${ }^{2}$.

\section{SALVACIÓN Y EXPIACIÓN EN EL CONTEXTO ACTUAL}

De entrada, la salvación parece una cuestión que actualmente no interesa en exceso. Algunos dicen, incluso, que es una oferta sin demanda. No obstante, al ir más allá de las apariencias podemos percibir que, aunque pocas personas se preguntan por su salvación con esta formulación clásica, sí existe en ellas el deseo de ser felices, vivir en plenitud y superar aquello que les hace mal (en el amplio sentido de la palabra: sufrimiento, fatalidad, finitud, pecado, muerte...).

La reflexión teológica cristiana tiene la difícil tarea de hacer accesible su propuesta soteriológica para la mentalidad actual. Esto requiere una actualización del vocabulario teológico, en una doble vertiente: profundizar en lo que aportan los términos soteriológicos clásicos y encontrar el lenguaje más apropiado para transmitir hoy su contenido ${ }^{3}$.

Si bien en el pasado se abusó de la comprensión hamartiológica de la salvación, con la consiguiente focalización en su aspecto negativo (salvación de), actualmente se está queriendo recuperar la parte más positiva (y

${ }^{1}$ Cf. Michael Kibbe. "Is it finished? When did it start? Hebrews, priesthood, and atonement in biblical, systematic, and historical perspective". The Journal of Theological Studies 65 (2014): 25-61 (46).

2 Esta palabra viene de «at-one-ment», es decir, hacer de dos partes una sola. Cf. Vincent Brümmer. Atonement, Christology and the Trinity: Making Sense of Christian Doctrine. Aldershot: Ashgate, 2005, 65. En realidad, significa básicamente «reconciliación», pero incluye en su significado todo el proceso redentor por la muerte y la resurrección de Cristo, con el matiz oneroso de dicho proceso. Por eso, cuando el contexto deje suficientemente claro si la palabra atonement está utilizada en el sentido general, preferimos traducirla por «redención» (para implicar el conjunto del proceso y su cariz cristológico); cuando se refiera al medio sacrificial por el que se lleva a cabo, la traduciremos por «expiación».

3 Sobre la tarea actual de la soteriología y su estatuto epistemológico, cf. Emilio J. Justo. "El estatuto epistemológico de la soteriología". Scripta Theologica 50 (2018): 303-319. 
de mayor importancia) de la soteriología (salvación para). Este cambio de perspectiva es necesario, pero puede suponer el peligro de relegar al olvido categorías que tienen un papel importante en la comprensión cristiana del hecho salvífico, pero que han sido dejadas de lado por el hecho de haber sido conceptos muy próximos a la «vertiente negativa» que apuntamos.

Sin embargo, estas categorías siguen presentes en la liturgia y la predicación de la Iglesia. En nuestra opinión, no se trata de orillarlas, sino de recuperar el significado que entrañan y conectarlo con esa comprensión positiva de la salvación como la relación de amor con Dios y con los demás seres humanos. Si no elaboramos pensamiento sobre ellas, se seguirán repitiendo las fórmulas antiguas sin que se tengan herramientas para profundizar en ellas y entenderlas.

Éste es el caso de categorías como "sacrificio», «muerte vicaria», «sustitución» o «satisfacción»; y creemos que ocurre especialmente con la categoría de «expiación». Es un concepto algo esquivo, que no acabamos de saber definir (ni siquiera el Diccionario teológico del Nuevo Testamento lo define, sino que más bien muestra algunas de sus consecuencias y rastrea sus usos) ${ }^{4}$, al que se han ido adhiriendo ideas que no pertenecen a la comprensión cristiana, quizá debido al uso primigenio del término (aplacar la ira de los dioses, conseguirse su favor), quizá a que se ha ido difuminando tras otras categorías a las que suele aparecer unido, como «sacrificio (expiatorio)», «muerte (expiatoria)», «(expiación) vicaria», y quizá también a que a lo largo de la Tradición se ha utilizado de manera casi intercambiable con términos como «satisfacción»o «sustitución penal». Se relaciona la expiación con el perdón de los pecados y con la eliminación de la culpa, pero no se suele precisar más.

Quizá por esta falta de pensamiento en torno al tema, encontramos accesos superficiales al mismo dentro de la propia teología y la predicación cristianas (accesos que, por otra parte, restan credibilidad a la fe ante la sociedad y las demás disciplinas científicas). Este tipo de aproximaciones no hacen justicia a la ontología simbólica desde la que ha de tratarse, pues proponen una lectura simplista de la expiación. Un ejemplo sería el bestseller de H. A. Maxwell Whyte, El poder de la sangre, en el que el

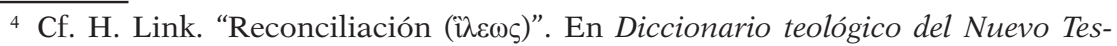
tamento, dirigido por Lothar Coenen, Erich Beyreuther y Hans Bietenhard, vol. 4, 38-41. Salamanca: Sígueme, 1984. 
autor realiza una interpretación casi física de la expiación por la sangre de Cristo $^{5}$.

Aunque este tipo de discurso no sea tan propio de la teología académica, sino más bien de la predicación y la divulgación, hay que dar una respuesta teológicamente fundada para responder de manera satisfactoria a estas interpretaciones. Si la teología no habla del tema y no lo hace bien, el interlocutor de las otras ciencias pasa a ser este discurso confuso que mezcla niveles de realidad y que no opera con la epistemología propia de las disciplinas teológicas.

Además, la expiación tiene un trasfondo antropológico muy importante. Cuando el ser humano obra mal y se arrepiente, siente la necesidad de reparar ese mal que ha hecho, de hacer lo posible por borrar su culpa y por detener las consecuencias de su acción. Y, como bien han ilustrado muchas obras literarias de todos los tiempos, hay momentos en los que el hombre no puede frenar el mal que su pecado ha generado.

Éste es el caso de la protagonista de la novela Expiación (Atonement, el original en inglés), de Ian McEwan ${ }^{6}$ : una acción de la protagonista, no guiada por la verdad sino por sus creencias y su despecho, lleva a un hombre inocente a un destino funesto. Ella no puede hacer nada por frenar las consecuencias de su acción y la única forma que encuentra de expiar su pecado es narrar la historia y reconocer su culpa. No obstante, al final de la obra parece reconocer que la expiación no es posible si no hay un ser superior que la realice:

«El problema a lo largo de estos cincuenta y nueve años ha sido el siguiente: ¿cómo puede una novelista alcanzar la expiación cuando, con su poder absoluto de decidir desenlaces, ella es también Dios? No hay nadie, ningún ser ni forma superior a la que pueda apelar, con la que pueda reconciliarse o que pueda perdonarla. No hay nada aparte de ella misma. Ha fijado en su imaginación los límites y los términos. No hay expiación para Dios, ni para los novelistas, aunque sean ateos. Esta tarea ha sido siempre imposible, y en esto ha residido el quid de la cuestión. La tentativa lo era todo» ${ }^{7}$.

${ }^{5}$ Cf. H. A. Maxwell Whyte. El poder de la sangre. New Kensington: Whitaker House, 2010, capítulo 2: "Expiación por la sangre".

6 Cf. Ian McEwan. Expiación. Barcelona: Anagrama, 2002.

7 Ibid., 434ss. 
La obra termina con esta reflexión desgarradora: que, pese a todos los esfuerzos de la novelista, la expiación no es posible en ausencia de un ser superior que la perdone. La película del mismo título, basada en la novela, cierra la narración con un toque más esperanzador: la autora pretende reparar su mal ofreciendo a los agraviados (el hombre acusado injustamente y su hermana, enamorada de él) una vida plena, aunque sea en la ficción ${ }^{8}$. Con todo, sigue quedando pendiente la pregunta por la trascendencia abierta en la novela.

El pueblo de Israel también identificó la apertura de la cuestión antropológica a la teológica, es decir, la necesidad de Dios para que la expiación fuera posible. En contraste con otros pueblos, entendió que Dios no es el objeto de la expiación, sino su sujeto. Dicho de otra manera, el pueblo no podía borrar las culpas y detener el mal, sino que Dios lo hacía y les otorgaba participar de ese don, acogerlo a través de ritos simbólicos.

\section{LA EXPIACIÓN EN EL CONJUNTO DEL A. T.}

A pesar de tratarse de un concepto bastante estudiado por los especialistas en el Antiguo Testamento, la "expiación» sigue siendo una cuestión controvertida y misteriosa; el texto bíblico apunta a esta realidad, pero no la define con precisión.

La raíz hebrea del verbo "expiar» es kpr (kipper $)^{9}$. No existe consenso exegético acerca de su etimología. Las dos posibilidades más plausibles son: a) que tenga su origen en el acádico kupuru, que significa "arrancar», «borrar» o «purificar cúlticamente» y b) que provenga del árabe $k f r$, cuyo significado es «cubrir» o "velar» ${ }^{10}$. En opinión de Milgrom, ambas no son incompatibles, sino que pueden ser complementarias, pues al fin y al cabo hacen referencia a algo que entra en contacto con la realidad que quiere purificarse ${ }^{11}$.

\footnotetext{
8 Atonement (en castellano, Expiación), dirigida por Joe Wright. Reino Unido, 2007.

9 Como indicamos en la introducción, nos centraremos en esta raíz por tratarse del término técnico para designar la expiación.

10 Cf. F. Maass. "Expiar". En Diccionario teológico manual del Antiguo Testamento, dirigido por Ernst Jenni y Claus Westermann, vol. 2, 1152-1171, aquí 1153. Madrid: Cristiandad, 1978.

${ }^{11}$ Cf. Jacob Milgrom. Leviticus 1-16. A new translation with introduction and commentary. Vol. 1. New York: Doubleday, 1991, 1079-1080.
} 
Una tercera opción es considerar que el verbo deriva del sustantivo antiguo kốfcer, que significa "precio de rescate». Contra esta hipótesis se suele objetar que el sustantivo no pertenece al ámbito cúltico y que «parece, más bien, un derivado secundario de $k p r$ piel (antes de convertirse en término cúltico fijo)» ${ }^{12}$.

La mayoría de las apariciones de $k p r$ en el Canon hebreo tiene lugar en el documento sacerdotal (en adelante, $\mathrm{P})^{13}$. El sustantivo kippūrìm, «expiación», solo aparece en P. Por este motivo, aunque comenzaremos con un breve recorrido del uso de la «expiación» en el conjunto del A. T., nuestro estudio se detendrá en el análisis del término en el documento sacerdotal.

Después nos aproximaremos a la dimensión intercesora de la expiación y profundizaremos en el posible carácter expiatorio del siervo de Yahveh del Deuteroisaías, de especial interés por el uso que los autores neotestamentarios hicieron del siervo en su lectura de lo acontecido en Jesucristo y que, por tanto, ilumina el análisis de la expiación en el Nuevo Testamento.

\subsection{ACLARACIÓN SEMÁNTICA}

En opinión de Stanislas Lyonnet, el significado de kipper «no debe ser determinado desde la etimología, sino principalmente desde la manera en que el verbo era utilizado por los hebreos» ${ }^{14}$. En el uso no ritual parece claro que en la forma activa el verbo se refiere a Dios, que perdona o quita el pecado ${ }^{15}$, y en la forma pasiva se refiere al pecado que es perdonado o quitado por Yahveh. Incluso cuando aparece explícitamente como sujeto

12 Ibid., 1154.

13 Cf. Ibid., 1155.

14 Stanislas Lyonnet. “The Terminology of 'Expiation' in the Old Testament”. En Sin, Redemption, and Sacrifice: A Biblical and Patristic Study, Stanislas Lyonnet y Léopold Sabourin. Rome: Biblical Institute Press, 1970, 120-136, aquí 127.

${ }_{15}$ En la misma línea se pronuncia François Bourassa. "Expiation". Science et Esprit 22, n. ${ }^{\circ} 2$ (1970): 149-170. Según él, tanto el verbo kipper como su traducción $\dot{\varepsilon} \xi i \lambda \alpha \dot{\alpha} \sigma \kappa \varepsilon \sigma \theta \alpha$ significan de manera preponderante la acción de Dios, que perdona y quita el pecado, y sólo secundariamente la acción necesaria por parte del pecador para que la expiación tenga lugar (a través de un castigo sufrido o del sacrificio ofrecido), cf. ibid., 151-152. Este autor entiende la acción humana como una respuesta a la iniciativa gratuita divina, cf. ibid, 153. 
otro personaje, como Moisés, Aarón o un sacerdote, Dios no es considerado objeto de la expiación, pues el objeto es el pecado que necesita ser quitado o el objeto o el lugar que necesita ser purificado.

En opinión de Lyonnet, el uso litúrgico es muy parecido: es Dios quien expía y el pecado el que es expiado. Esta comprensión de la expiación es coherente con la traducción que las versiones antiguas hicieron del término (aunque, como veremos, con algunos matices).

Para apreciar la diferencia entre la concepción que el Antiguo Testamento maneja y la del mundo pagano resulta útil comparar el uso del verbo griego equivalente a «expiar» ( $\dot{\varepsilon} \xi \lambda \alpha \dot{\alpha} \sigma \kappa \varepsilon \sigma \theta \alpha \iota)$ en la Septuaginta y en el lenguaje griego profano.

El verbo $\dot{\varepsilon} \xi \lambda \lambda \alpha ́ \sigma \kappa \varepsilon \sigma \theta \alpha$ se utiliza en griego teniendo como sujeto al ser humano y como objeto un dios, un héroe o alguien que ha muerto; en todo caso, alguien a quien hay que "aplacar» ${ }^{16}$. Con todo, no siempre se trata de calmar la ira despertada por la culpa propia, sino que a veces se busca hacer al dios propicio a las necesidades del hombre ${ }^{17}$. Lyonnet señala que el verbo también se utiliza con un significado cercano a «sobornar» cuando se trata de obtener la benevolencia de otro hombre.

Por su parte, los LXX retienen el uso profano del verbo, aunque cambian notablemente su uso en el ámbito religioso ${ }^{18}$. Como ya hemos señalado, en el A. T. «expiar» no significa aplacar ni propiciar, sino quitar el pecado (aunque, a juicio de Lyonnet, Dios sea «apaciguado» cuando el mal ha

\footnotetext{
16 Para lo que sigue, cf. Lyonnet. "Expiation' in the Old Testament”, 124ss.

17 De todos modos, A.-J. Festugière interpreta que el «intercambio» al que hace referencia la plegaria griega helenística (en la que el fiel promete algo a la divinidad si ésta le es propicia en algo concreto que pide) no debe interpretarse como un mero comercio, sino como una reciprocidad entre el ser humano y los dioses entendida como relación de amistad y amor, en el marco de la cual se hacen regalos y se espera

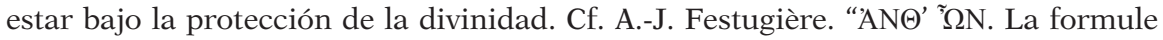
'en échange de quoi' dans la prière grecque hellénistique”. Revue des Sciences philosophiques et théologiques 60 (1976): 389-418, especialmente pp. 413ss. En una línea parecida cf. Frédéric Lenoir. Breve tratado de historia de las religiones. Barcelona: Herder, 2018, 41-45. Entendida la imagen del intercambio desde este paradigma de relación interpersonal, sí tiene aplicación en el universo conceptual del A. T., pues la expiación es comprendida de manera relacional como algo que sucede entre Dios y el ser humano.

${ }^{18}$ Cf. Lyonnet. "The Terminology of 'Expiation' in the Septuagint”. En Sin, o. c., 137 ss.
} 
sido quitado $)^{19}$. Por eso, en la Septuaginta el verbo $\dot{\varepsilon} \xi 1 \lambda \alpha ́ \sigma \kappa \varepsilon \sigma \theta \alpha$ se conjuga de maneras poco comunes en el uso profano para buscar la equivalencia con la construcción hebrea, en la que Dios aparece como sujeto y no como objeto de la expiación. Los pocos casos en los que Dios es el objeto no deben entenderse desde el paradigma de la propiciación sino, como veremos, desde la comprensión veterotestamentaria de la intercesión.

\subsection{PRINCIPALES TeXtos EN LOS QUe APARECEN «KIPPER» Y DERIVADOS}

Del verbo kpr (kipper) piel, «expiar», deriva el sustantivo kippūrìm, «expiación», que, como señalábamos anteriormente, sólo se encuentra en textos de P (Éx 29,36; 30,10.16; Nm 5,8; 29,11; Lv 23,27.28; 25,9) ${ }^{20}$.

El sustantivo kốfcer, que también mencionamos como derivado de $k p r$ piel «aparece ya en el Código de la Alianza y en Amós; pertenece a la esfera del ius civile y significa "indemnización, precio de rescate" (Éx 21,30; 30,12; Nm 35,31s; Is 43,3; Sal 49,8; Job 33,24; 36,18; Prov 6,35; $13,18 ; 21,18)$ o "dinero de soborno" (1Sm 12,3; Am 5,12)» ${ }^{21}$. A través de este pago o rescate, se soluciona el daño, se absuelve al culpable y se consigue la reconciliación ${ }^{22}$.

No es claro si kappỗcet, el término que designa la cubierta del arca de la alianza, procede de $\mathrm{kpr}$ piel. El vocablo aparece 27 veces, siempre en P (Éx 25-31; 35-40; Lv 16 y Nm 7,89), excepto 1Cr 28,11. Es posible que en un principio designara el santuario mismo, no la cubierta del arca.

19 Según el Diccionario Bíblico HarperCollins, la propiciación no responde tanto al testimonio bíblico como la expiación. La primera se refiere al sujeto con el que se ha roto la alianza (Dios, al que se quiere aplacar), mientras que la segunda se dirige a aquello que ha roto la relación, que es el pecado, con el objeto de quitarlo, limpiarlo y perdonarlo. Cf. John E. Alsup. "Expiation”. En The HarperCollins Bible Dictionary, ed. revisada, editado por Paul J. Achtemeier, 319-320. San Francisco: HarperSanFrancisco, 1996. Con todo, desde una comprensión relacional de la expiación, la imagen del aplacamiento tiene su sentido, aunque no deba llevarse la metáfora más allá de ciertos límites. Aunque, como veremos, la expiación hace referencia a quitar el pecado (por parte de Dios), es también cierto que esto permite la disposición de ambas partes a la reconciliación, a lo que apunta, a su manera, la idea de aplacamiento.

20 Para lo que sigue cf. Maass. "Expiar", 1154ss.

21 Ibid.

22 Cf. Bourassa. "Expiation", 154; Pietro Bovati. Ristabilire la giustizia. Roma: Editrice Pontificio Istituto Biblico, 1986, 178. 
El verbo $k p r$ se encuentra 101 veces en el Canon hebreo ${ }^{23}$. Tres cuartos de los casos están en P; los demás aparecen en Ez (seis veces), Is (cinco veces), Dt, Sal y $1 / 2 \mathrm{Cr}$ (tres veces), 1/2Sm y Prov (dos veces) y una vez en Gn, Éx, Jr, Dn y Neh. Por cada 9 casos exílicos y posexílicos sólo encontramos uno preexílico. Tanto Ezequiel como la obra histórico-cronista se ajustan a la comprensión que $\mathrm{P}$ tiene de la expiación. Entre los demás casos encontramos algunos más próximos al concepto cultual de expiación y otros cuyo contexto no cultual invita a pensar en un significado más próximo a «perdón».

Sólo hay tres casos en el A. T. en los que la expiación es presentada como un proceso en el que el sujeto es el ser humano ${ }^{24}$ : Gn 32,21 (Jacob quiere expiar el rostro de Esaú con regalos; equivaldría a decir que quiere suavizarlo), Prov 16,6 (con amor y lealtad se expía la falta; aquí el significado es más cercano a «reparar») y Prov 16,14 (el hombre sabio puede expiar la ira de Dios, parece querer decirse que quiere apaciguarla).

En los casos en los que tiene lugar entre hombres, la expiación permite regular los conflictos mediante la compensación y no con sanciones o violencia. "La meta de la expiación es la reconciliación gracias al reconocimiento de una responsabilidad (civil) y a la compensación dada. La expiación reemplaza el conflicto por el acuerdo mutuo y la pena por una compensación», aunque, como tal, no implica sustitución; sí suele haber una figura mediadora ${ }^{25}$.

\section{LA EXPIACIÓN EN EL DOCUMENTO SACERDOTAL}

El uso del término «expiar» es eminentemente postexílico y, como acabamos de señalar, propio de $\mathrm{P}$, que lo emplea en el marco de los sacrificios cultuales ${ }^{26}$. En este contexto, la expiación tiene relación con el pecado y la impureza. Por consiguiente, es fundamental acercarse primero a la

${ }^{23}$ De esas 101 veces, en 92 de ellas el verbo aparece en piel (49 en Lv, 15 en Nm, siete en Éx y seis en Ez), 7 en pual (cuatro de las cuales están en Isaías), una sola en hitpael $(1 \mathrm{Sm} 3,14)$ y otra en nitpael (Dt 21,5). Cf. Maass. "Expiar", 1155.

${ }^{24}$ Cf. Ibid., 1166.

25 Adrian Schenker. “Expiación”. En Diccionario Crítico de Teología, dirigido por Jean-Yves Lacoste, 482-484. Madrid: Akal, 2007.

${ }^{26}$ Cf. Horst Dietrich Preuss. Teología del Antiguo Testamento. Vol. 2. Bilbao: Desclée de Brouwer, 1999, 309-310. 
concepción israelita del pecado y la impureza y, en concreto, a la comprensión que de ambas realidades tiene $\mathrm{P}$, para poder entender de manera cabal el papel de la expiación en referencia a las mencionadas realidades.

\subsection{Pureza e impureza}

En el postexilio Israel se organiza en torno a la Ley y el Templo ${ }^{27}$. Se subraya la santidad de Dios y la comunidad israelita aspira a vivir en pureza ante él. La pureza, además de permitirle acercarse al Santo por excelencia, lo caracteriza como nación elegida por él. Hay, por tanto, «una correspondencia entre la "santificación" de Israel y su "separación" de entre las naciones» ${ }^{28}$.

No obstante, si bien la pureza y la santidad están muy relacionadas, no pueden identificarse ${ }^{29}$. La pureza (ritual) hace referencia al deseo de mantener el orden establecido por Dios en la creación. La santidad trasciende lo ritual y se adentra en lo moral. En todo caso, tanto un pecado (moral) como una transgresión de tipo ritual perturban el orden de lo creado. Por eso el ser humano es responsable de ambos actos y P busca restaurar el orden perdido en ellos a través del culto.

Como apunta Milgrom, para la teología sacerdotal la santidad está relacionada con la vida y la impureza con la muerte. De ahí que las normas de pureza ritual estén en general destinadas a rehuir el contacto con la muerte y promover la defensa de la vida ${ }^{30}$.

En opinión de Hayes, el contacto con la impureza del pueblo iba contaminando el santuario de Yahveh hasta que él ya no podía habitar en él

27 Cf. Ianire Angulo Ordorika. “'Tu pueblo será mi pueblo y tu Dios será mi Dios' (Rut 1,16). El libro de Rut: creer en tiempos inciertos". Proyección LXV (2018): 267290, aquí 269 ss.

${ }_{28}$ Félix García López. El Pentateuco. Estella: Verbo Divino, 2002, 216. La elección y la alianza son el fundamento de la ley de santidad del Levítico. El pueblo, propiedad de Dios, debe aspirar a la pureza y la santidad y evitar el pecado. Cf. Louis Moraldi. "Expiation”. En Dictionnaire de Spiritualité. Ascétique et Mystique. Doctrine et Histoire, dirigido por M. Viller, F. Cavallera y J. de Guibert. Vol. 4, 2026-2045, aquí 2026ss. Paris: Beauchesne, 1960.

${ }^{29}$ Cf. García López, 215ss.

30 Cf. Milgrom. Leviticus, 46. 
y había que limpiarlo o purificarlo ${ }^{31}$. Esto sucedía como consecuencia tanto de la impureza física como de la impureza moral o pecado, y por eso era necesario restaurar el orden tanto en un caso como en el otro.

\subsection{El PeCADO y SUS CONSECUENCIAS}

En el A. T. el pecado se entiende como una ruptura, principalmente con Dios, pero también con el prójimo ${ }^{32}$. Además, se trata de una realidad objetiva que tiene consecuencias negativas, en primer lugar, para el propio pecador y, en segundo lugar, para toda la realidad que lo rodea: su comunidad, sus relaciones, sus cosas, la tierra... La tradición se ha referido a esta dimensión objetiva del pecado como "pena», mientras que la «culpa» hace referencia a la vivencia subjetiva que la persona tiene de su pecado (una vez que se ha hecho consciente del mismo) ${ }^{33}$.

En el horizonte teológico de $\mathrm{P}$, el pecado trae consigo un castigo. El castigo «es una necesidad, primero porque la ofensa hecha a Dios debe ser reparada; y a continuación porque hay que eliminar del pueblo el veneno contagioso que es el pecado, y, finalmente, porque el pecador mismo debe ser corregido» ${ }^{34}$. El castigo, por tanto, es la interpretación creyente de las consecuencias inmanentes al propio mal, y tiene como objetivo la conversión del pecador y la reparación por su parte de la situación que ha generado ante Dios, ante la comunidad y ante sí mismo para poder restablecer todas las relaciones rotas por su pecado.

La ruptura de la relación se sana mediante el perdón. Ahora bien, para que esta sanación sea posible, tiene que haber reconocimiento del mal cometido por parte de la persona (a esto apunta la reparación requerida por el castigo, como acabamos de señalar) y deseo de que Dios restaure la situación. Como después veremos, los sacrificios cumplen una función importante en este proceso de reconciliación: permiten al pecador reconocer su culpa y a través de ellos Dios interviene expiando el mal.

${ }^{31}$ Cf. John H. Hayes. "Atonement in the Book of Leviticus". Interpretation 52 (1998): 5-15, aquí 6-7. Véase también Milgrom. Leviticus, 43.

32 Cf. Edmond Jacob. Teología del Antiguo Testamento. Madrid: Marova, 1969, 263 ss.

33 Cf. Juan Luis Ruiz de la Peña. La pascua de la creación: Escatología, 2. a ed.

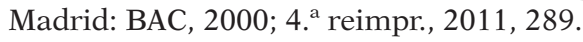

34 Jacob, 268ss. 
Para una adecuada profundización en la idea de expiación, resulta importante insistir en el carácter objetivo del pecado. Si bien el pecado es la ruptura de una relación (carácter intersubjetivo), para el A. T. es central la comprensión objetiva tanto del pecado como de sus consecuencias. Éstas a veces escapan a la capacidad de reparación del propio pecador y por eso sólo Dios puede realmente hacerse cargo de ellas. Ése es el objetivo de determinado tipo de sacrificios. La detención o destrucción del mal en ellos no siempre exime al pecador del castigo, pero sí de su carácter condenatorio.

\subsection{LOS SACRIFICIOS CULTUALES}

Los sacrificios a los que alude el Levítico son ritos que ponen en relación con Dios ${ }^{35}$. Lo que se ofrece en ellos

«[...] constituye la alimentación básica de los israelitas — cereales-y la materia de una comida festiva - cabezas de ganado y vino-. Pero es también lo que constituye el principal producto de su trabajo - de su ganadería y de su agricultura-y que es representativo de la riqueza de la tierra que Dios les ha dado» ${ }^{36}$.

De esta manera, los israelitas retornaban estos dones a Dios, agradecidos a él por haberles entregado todo. Son ritos, por tanto, que se celebran en el marco de la comunión con Yahveh. En Lv 1-7 aparecen cinco sacrificios principales, más la libación ${ }^{37}$.

Los tres primeros son los sacrificios de aroma agradable: el holocausto ( Lv 1), la ofrenda vegetal ( Lv 2) y el sacrificio de comunión ( $\operatorname{Lv} 3$ ). Los otros dos son sacrificios de absolución: por el pecado o sacrificio expiatorio ( $\operatorname{Lv} 4,1-5,13)$ y de reparación por determinado tipo de pecados (Lv 5,14-26). En Lv 6-7 se explica la utilización de los sacrificios por parte

35 Según Médebielle los sacrificios del código levítico ya están prefigurados antes, aunque no aparezcan desarrollados como tales hasta ese momento. Cf. A. Médebielle. L'expiation dans l'Ancien et le Nouveau Testament. Rome: Institut Biblique Pontifical, 1923, 9-31. 2002, 16.

${ }^{36}$ Alfred Marx. Los sacrificios del Antiguo Testamento. Estella: Verbo Divino,

37 Cf. ibid., 14. 
de los sacerdotes y los fieles; la parte dedicada a los primeros es mucho más extensa que la referente a los segundos.

Los sacrificios de aroma agradable parecían ir destinados a la relación o la comunión con Dios, mientras que los de absolución tenían como objetivo la restauración de esa comunión cuando se había roto o dañado debido a la transgresión humana. De todos modos, como señala von Rad, aunque Lv 1-5 da muchos detalles sobre cómo realizar los sacrificios, «no da casi ninguna explicación del significado de los ritos» ${ }^{38}$. Por ello resulta difícil la aproximación teológica a ellos.

\subsection{LOS SACRIFICIOS EXPIATORIOS}

Nos detenemos en los dos sacrificios de absolución debido a que son los relevantes para nuestra investigación. El primero de ellos es el sacrificio expiatorio, hattat ${ }^{39}$ (cf. Lv 4,1-5,13), el más frecuente en P y que casi siempre aparece en las diversas combinaciones de sacrificios ${ }^{40}$. Se trata de un sacrificio que liberaba al que lo ofrecía de sus pecados involuntarios, normalmente relacionados con las normas de pureza ritual. También se utilizaba para volver a consagrar algo profanado. La ofrenda consistía en un animal (uno u otro dependiendo de la persona), o una ofrenda vegetal para quien era pobre y no podía permitirse comprar un animal.

El segundo es el sacrificio penitencial o de reparación, 'ašham (cf. Lv 5,1426). Éste expiaba pecados no involuntarios; parece que cuando se cometía una ofensa contra la propiedad divina (es decir, cuando alguien se apropiaba algo que era de Dios), ante casos de sacrilegio y al jurar en falso. En este sacrificio la ofrenda estaba siempre constituida por un carnero o un cordero.

En opinión de von Rad, es muy difícil establecer una distinción nítida entre ambos grupos, puesto que «la ley sobre los sacrificios en Lev 1-6 es sólo un intento posterior por organizar la diversidad de sacrificios preexistentes. Los usos cultuales que le precedieron tenían sin duda un aspecto más polícromo en los diversos santuarios y en épocas tan distantes ${ }^{41}$.

\footnotetext{
${ }^{38}$ Gerhard von Rad. Teología del Antiguo Testamento. 7. a ed. Vol. 1. Salamanca: Sígueme, 1993, 318.

39 El término hattat designaba a la vez el pecado, el sacrificio por el pecado y la víctima de ese sacrificio; cf. Moraldi. "Expiation”, 2028.

40 Cf. von Rad, 326.

41 Ibid., 328.
} 
Como se ha indicado ya, no se sabe con certeza lo que significa el término «expiar». Se trata de un término técnico del culto, pero su significado no está claro ni por la etimología, aún en discusión por parte de los exegetas, ni por su evolución conceptual. Ya hemos dicho que el verbo hebreo $\mathrm{kpr}$ describe principalmente la acción de Dios, pero parece que también se refiere a la acción del sacerdote en los sacrificios (como mediador entre Dios y los hombres). Esa acción no se dirige hacia la persona misma, sino hacia la contaminación resultante de su pecado o impureza ${ }^{42}$. Dicho de otro modo: se expía el pecado, no el pecador, aunque la expiación tiene lugar para que el pecador pueda ser reconciliado.

Hayes señala que para realizar el proceso de retorno a una buena relación con Dios mediante el sacrificio hattat era necesario que el pecador se sintiera culpable e hiciera una ofrenda de purificación ${ }^{43}$. En el caso del sacrificio 'ašham, el proceso tendría cuatro pasos (cf. Lv 6,1-7):

1. El pecador experimenta la culpa (v. 4).

2. Debe confesar lo que ha hecho.

3. Debe restituir lo que ha quitado a la víctima más un $20 \%$.

4. Presenta un carnero a Dios como reparación por el sacrilegio ${ }^{44}$.

Simplificando, se trataría de que no faltara ni el arrepentimiento, ni la confesión (es decir, el reconocimiento público), ni la restitución (a la víctima), ni el sacrificio expiatorio para restaurar la relación con Dios. Como puede apreciarse, en el segundo tipo de sacrificio tiene un peso mayor la responsabilidad que recae sobre el creyente en cuanto a la confesión y la restitución (de hecho, por eso se llama «sacrificio de reparación») ${ }^{45}$.

De lo dicho con anterioridad no debe extraerse la idea de que la expiación es obra del pecador. Sí requiere que éste se involucre, reconozca el mal cometido y quiera la liberación del pecado. Sin embargo, quien expía es $\operatorname{Dios}^{46}$. Como señala W. Eichrodt, «el Código sacerdotal pone gran acento

${ }^{42}$ Cf. Hayes. "Atonement", 9.

${ }^{43}$ Cf. ibid., 10-11.

${ }^{44}$ El valor de esta ofrenda material es siempre el don del corazón y la sumisión interior que simboliza, cf. Médebielle, 15.

45 Cf., en la misma línea, Moraldi. "Expiation”, 2029.

46 Esto no impide que el A. T. subraye la dimensión ética, en contraposición a la visión pagana del sacrificio: el creyente no sólo debe practicar el rito, sino también vivir de acuerdo con la ley de Dios para que su sacrificio sea aceptable, como veremos al tratar la crítica profética del sacrificio. Cf. Terry Briley. "The Old Testament 'Sin Offering' and Christ's Atonement”. Stone-Campbell Journal 3 (2000): 89-101, aquí 94. 
en el hecho de que la expiación ha sido instituida y mandada por el mismo Dios, y fundamenta su eficacia precisamente en esa voluntad divina $»^{47}$.

H. D. Preuss explica también este punto y además esclarece la relación entre la expiación y el perdón:

«La unión de expiación y perdón en los sacrificios realizados por pecados humanos no ha de entenderse en el sentido de que la expiación es la condición para que puedan ser perdonadas las culpas del hombre, de que el hombre ha de hacer primero algo a lo que luego Dios responde y reacciona; sino que tanto la expiación como el perdón son dones y obras de Dios, que parten de Él y de las que el hombre es beneficiario. En el acto expiatorio el fin que se busca es tanto la expiación como el perdón. Yahvé lleva a cabo el perdón a través de la expiación, y el sacerdote ejecuta (solamente) la acción expiatoria» ${ }^{48}$.

Tanto el sacrificio hattat como el 'as̄ham son calificados por el Levítico como «expiatorios» y el proceso es parecido en ambos. El texto subraya la centralidad de la aspersión de la sangre del animal sacrificado para la expiación. En Lv 17,11 se ofrece en cierto modo una explicación de ello: se dice que la vida está en la sangre y que es la sangre la que opera la expiación por una persona.

No está claro a qué se refiere exactamente el texto de Lv 17,11. Podría tratarse de que el derramamiento de la sangre de un ser vivo fuera un símbolo del ofrecimiento de la vida a Dios. En opinión de Marx, la función de la sangre es repeler la muerte y llevarse «todo lo que impide la comunicación con Dios» ${ }^{49}$. De todos modos, a juicio de Childs, «La conexión entre el poder de expiación y la vida en la sangre es algo que se supone por doquier, pero que en ninguna parte se articula plenamente ${ }^{50}$.

\subsection{El DÍA DE LA EXPIACIÓN}

En Lv 16 se narra el ritual que el pueblo de Israel realizaba cada año el día conocido como «día de la expiación» (Yom Kippur). Parece que en

\footnotetext{
47 Walther Eichrodt. Teología del Antiguo Testamento. Vol. 1. Madrid: Cristiandad, 1975, 149.

48 Preuss, 306.

49 Marx, 22.

50 Brevard S. Childs. Teología bíblica del Antiguo y del Nuevo Testamento. Salamanca: Sígueme, 2011, 515.
} 
esta fiesta se querían expiar los pecados y las faltas que a lo largo del año no eran expiadas por medio de los sacrificios ${ }^{51}$. El texto relata varios ritos que Aarón debe hacer en el Santuario, en la Tienda de reunión y en el Altar (cf. Lv 16,20) para hacer expiación por todo el pueblo. Estos sacrificios corresponden a los ya descritos sacrificio expiatorio y sacrificio de reparación por el pecado y consisten en la inmolación del macho cabrío y la aspersión de la sangre en los diversos lugares que Yahveh va indicando.

La novedad de este ritual reside en que el Señor ordena a Aarón que apoye sus manos sobre la cabeza de un macho cabrío vivo, confiese todas las faltas y pecados de los hijos de Israel y deje marchar al animal al desierto, llevándose, así, las iniquidades lejos del pueblo (cf. Lv 16,20-22). Se trata de un ritual de carácter perpetuo:

«Celebrará el rito expiatorio del Santo de los Santos, de la Tienda de reunión y del Altar; también hará expiación por los sacerdotes y por todo el pueblo de la comunidad. Esto lo tendréis como estatuto perpetuo para celebrar expiación de los hijos de Israel de todos sus pecados, una vez al año» (Lv 16,33-34).

Que Yahveh ordenara realizar este ritual una vez al año para la expiación de todo el pueblo sugiere la gran importancia que la realidad del pecado y la necesidad de su expiación tenían para Israel.

La cuestión del macho cabrío enviado al desierto genera bastantes controversias entre los exegetas. Parece haber unanimidad en que esta parte del rito significa la eliminación del mal. Menos clara es la interpretación de la imposición de manos sobre él. Puede ser símbolo de una transferencia de pecado, pero no parece ser entendida como una sustitución. En todo caso, a través de esta parte del rito ha quedado incorporada la eliminación del pecado a la idea de expiación ${ }^{52}$. Con todo, parece que tenía un carácter más bien simbólico y que, aunque se tratase de un rito popular, era secundario respecto al rito previo de aspersión de la sangre ${ }^{53}$.

${ }^{51}$ Cf. Médebielle, 102.

52 Cf. Preuss, 394-396. Aunque hay autores, como A. Médebielle (cf. o. c., 148) y R. Dussaud, que mantienen la idea de sustitución, lo más frecuente es que los exegetas se sumen a la opción de Preuss (así, por ejemplo, J. Herrmann, J. Pedersen, A. Bertholet, A. R. S. Kennedy, W. R. Smith, D. Schötz o W. Eichrodt), cf. Moraldi. "Expiation", 2031.

${ }_{53}$ Cf. Moraldi. "Expiation”, 2032 y Médebielle, 105ss. El rito de expulsión del macho cabrío no produciría por sí mismo la expiación, sólo mostraría de forma figurada sus efectos, cf. ibid., 111. 


\section{LA DIMENSIÓN INTERCESORA DE LA EXPIACIÓN}

Aunque, como hemos visto, en la mayoría de los casos la expiación aparece como acción «descendente», es decir, de Dios hacia el ser humano — si bien es necesaria la participación de éste-, a lo largo del A. T. está también presente la dimensión intercesora de la expiación, que subraya el carácter ascendente del concepto.

\subsection{La EXPIACIÓN COMO PLEGARIA DE INTERCESIÓN EN LAS TRADUCCIONES ANTIGUAS}

Las traducciones antiguas de la Escritura nos permiten un primer acercamiento a esta vertiente del concepto por su constante subrayado de la intercesión o la plegaria a la hora de traducir la expiación y sus derivados ${ }^{54}$.

Mientras que los LXX por lo general traducen el verbo kipper por $\dot{\varepsilon} \xi \lambda \lambda \alpha ́ \sigma \kappa \varepsilon \sigma \theta \alpha 1$, san Jerónimo en la Vulgata lo traduce con frecuencia por «rezar» (orare) y derivados, como «implorar» (rogare) o «rogar» (deprecari), aunque también utiliza el término expiare, así como «purificar». En opinión de Lyonnet, el propio texto bíblico favorece esta interpretación de la expiación como plegaria de intercesión, puesto que no son pocos los ejemplos en los que ambas están relacionadas (sobre todo en los casos que veremos seguidamente). Así, la oración de intercesión sería una respuesta del creyente a Dios en el marco de la expiación.

El testimonio de las demás versiones latinas antiguas es tan claro como el caso de la Vulgata a la hora de comprender la expiación como intercesión, donde la oración es asimilada a la propiciación y ésta al perdón de los pecados.

La versión siríaca, sin embargo, traduce «expiar» por un verbo derivado de «santo», «puro», que podría traducirse como «limpiar» o «purificar». Este significado se aproxima más a la comprensión que tiene $\mathrm{P}$ de la expiación.

La versión aramea del Targum utiliza la misma raíz que el hebreo, kapper. Los diccionarios traducen este término por «limpiar», "quitar» o «borrar». No obstante, en diversos pasajes del Targum subyace la

\footnotetext{
${ }^{54}$ Cf. Lyonnet. “Expiation' in the Old Testament”, 131s; Íd. "Expiation et intercession. Note complémentaire: le témoignage des anciennes versions latines". Biblica 41, n. ${ }^{\circ} 2$ (1960): 158-167; Íd. "Expiation et intercession. A propos d'une traduction de saint Jerôme”. Biblica 40, n. ${ }^{\circ} 3$ (1959): 885-901.
} 
concepción de la expiación como intercesión (Nm 17,11-12; 16,46-47; Is 53,7$)$ y se utiliza otro verbo diferente de kapper.

Por otra parte, la fiesta de la expiación, Yom Kippur, es comprendida como una fiesta de oración (así lo interpretan Filón y el judaísmo palestinense; en el Talmud las palabras pronunciadas en el ritual son consideradas esenciales para que se produzca la expiación). A juicio de Lyonnet esta espiritualización de la noción de expiación pertenece a la propia tradición judía y por eso no es extraño que las diversas traducciones la hayan recogido. El carácter intercesor o mediador es, en primer lugar, atribuido a los sacerdotes, modelos de otra intercesión o mediación. En este punto hay una relación directa con la noción cúltica de expiación, en la que el sacerdote tiene un papel central.

\subsection{Expiación no cultual en el Pentateuco}

En un interesante artículo en el que analiza el pecado y la expiación en el Pentateuco, Jay Sklar explica con claridad y profundidad los tres tipos de pecado que encontramos en los primeros libros de la Escritura ${ }^{55}$.

Tras un minucioso análisis, Sklar concluye que hay dos tipos de pecado que pueden expiarse a través de los sacrificios: se trata de los pecados no intencionados y de los pecados cometidos con intención, pero que no son totalmente injustos (es decir, no socavan de raíz la relación con Yahveh). El tercer tipo de pecado es el injusto o arbitrario (en inglés, high-handed), aquél que supone una apostasía o rebelión contra Dios y que, por tanto, atenta contra la base de la relación con él, que es su alianza. Este pecado no puede ser expiado por medio de sacrificios.

En opinión del autor, Nm 15 sólo menciona los dos extremos del espectro (los pecados no intencionados y los muy graves) para advertir al israelita de que debe evitar los segundos e intentar mantenerse lo más alejado posible de ellos, para lo cual es mejor que se fije en las faltas inintencionadas y que procure evitar las intencionadas (ya que éstas llevan fácilmente al pecado grave).

¿Significa lo anterior que el pecado grave no puede ser expiado? En opinión de Sklar, que no pueda ser expiado a través de un sacrificio no

55 Cf. Jay Sklar. "Sin and Atonement: Lessons from the Pentateuch". Bulletin for Biblical Research 22 (2012): 467-491. 
significa que no pueda ser expiado en absoluto. Como la expiación sacrificial, la no sacrificial también requiere confesión y arrepentimiento por parte del pecador. La cuestión que se plantea es:

«Pero, asumiendo que este arrepentimiento tiene lugar, ¿cómo se consigue la expiación por el pecado injusto/grave? ¿Y cómo difieren los resultados, si lo hacen, de la expiación conseguida por medio del sacrificio? ${ }^{56}$.

Para responder a estas preguntas, Sklar analiza las semejanzas entre siete narrativas del Pentateuco en las que se produce un pecado grave y su expiación ${ }^{57}$. En todas estas historias, el pueblo cometió un pecado grave que merecía un castigo acorde y el Señor no lo rechazó por completo gracias a la acción de un mediador que consiguió que la relación entre Dios y su pueblo pudiera continuar. Que la expiación había tenido lugar se puede percibir no sólo en la restauración de la relación, sino también en el empleo de vocabulario asociado con ella.

Sklar destaca que, pese a que gracias al mediador Dios no rompe con el pueblo, sí hay, en todos los casos, algún tipo de castigo. Es decir, Dios perdona (la culpa, la dimensión subjetiva, la ruptura de la relación), pero no evita todas las consecuencias negativas del pecado del pueblo (la pena, las consecuencias objetivas). En opinión del autor, esto no atenta contra la misericordia divina, puesto que Dios, la parte ofendida, ha decidido perdonar cuando no tenía obligación de hacerlo ${ }^{58}$.

\subsection{LA ORACIÓN Y EL SUFRIMIENTO DEL JUSTO COMO EXPIACIÓN}

En una obra monográfica sobre la expiación en el Antiguo Testamento, Alexis Médebielle distingue dos maneras de expiar los pecados para el

56 Ibid., 486.

57 Se trata de Éx 32,1-34,28; Nm 11,1-3; 14,1-35; 16,1-175; 17,6-15; 21,4-9 y 25,1-13. Cf. ibid.

${ }^{58}$ Se apunta, así, también a que el castigo es la consecuencia inmanente del propio pecado en su dimensión objetiva y no algo puesto en marcha por la voluntad divina para «hacer pagar» al pecador. Por eso, aun habiendo perdón y reconciliación, siguen quedando consecuencias del mal. En todo caso, para el horizonte bíblico el castigo tiene el objetivo de llevar al pecador a la conversión y no tanto «hacerle pagar» por lo que ha hecho (desde una concepción punitiva). 
pueblo judío ${ }^{59}$. El primero es el sacrificio, del que ya hemos tratado. El segundo es la oración y el sufrimiento del justo ${ }^{60}$.

$\mathrm{El}$ autor no se detiene únicamente en los textos en los que aparece de forma explícita la palabra «expiación», sino que rastrea la idea subyacente a ella en otros textos del A. T. que pueden arrojar luz sobre su comprensión. Desde el comienzo de la Escritura la plegaria y el mérito del justo son elementos que Dios toma en consideración a la hora de perdonar al culpable. Un ejemplo de ello es la plegaria de Abraham para que Dios perdone a Sodoma y Gomorra por los justos que pudiera haber en ellas ${ }^{61}$. El otro gran ejemplo es Moisés, que intercede ante Yahveh para que perdone a su pueblo.

«Después de Abraham y Moisés, los dos grandes fundadores de la nación, la tradición de la oración expiatoria continúa de siglo en siglo ${ }^{62}$; los israelitas recurren a la intercesión de santos y profetas cuando no osan apelar directamente a Yahveh. Los justos tienen mayor crédito ante Dios, y esto beneficia a todo el pueblo debido a la solidaridad que hay entre todos los israelitas. Incluso los méritos de los padres ya muertos alcanzan a los creyentes.

Una mala comprensión del carácter social de los méritos, así como de las culpas, tuvo que ser corregida por el profeta Ezequiel, quien puso de relieve la importancia de la actuación personal como contrapunto $^{63}$. Esto no invalida, para Médebielle, el valor de la intercesión, sino que subraya la importancia que también tiene la responsabilidad individual.

Tras ofrecer algunos ejemplos más en los que la intercesión de los justos sirve como expiación para el resto del pueblo, el autor recalca que esta dimensión no llega a su cumbre hasta el siervo sufriente del Deuteroisaías, en el que hay un salto cualitativo en la concepción de la expiación.

${ }^{59}$ Cf. Médebielle, o. c.

${ }^{60}$ Cf. también una reflexión más breve en la misma línea en Moraldi. "Expiation", 2033ss.

${ }^{61}$ Cf. Médebielle, 166ss.

62 Ibid., 169.

${ }^{63}$ Cf. ibid., 175ss. 


\subsection{LA CRÍTICA PROFÉTICA AL CULTO SACRIFICIAL}

Los profetas (por ejemplo, Isaías, Jeremías y Zacarías) no criticaron el culto en sí, sino la falsa seguridad que éste otorgaba a los israelitas cuando se confiaban y pensaban que podían obtener la benevolencia divina de manera automática en cuanto realizaran los rituales conforme a las normas establecidas ${ }^{64}$. La cuestión en juego para la crítica profética no era, por tanto, el sistema sacrificial, sino la pureza de intención de quienes lo practicaban. El sacrificio es idolatría si no lleva al compromiso con el prójimo, concretamente con el más necesitado ${ }^{65}$.

De todos modos, la realidad del sacrificio fue evolucionando y tendió a la espiritualización, pero parece que este proceso se comenzó a dar en el judaísmo intertestamentario y se consolidó en el Nuevo Testamento ${ }^{66}$. En opinión de Alfred Marx, la espiritualización del sacrificio no sería del todo propia del Antiguo Testamento, aunque haya textos, como Os 14,3, que ya apunten en esta dirección ${ }^{67}$. Esto daría pie a pensar que la dimensión intercesora de la que venimos tratando no tiene por qué ser considerada necesariamente como una evolución desde la comprensión cúltico-sacrificial, sino que puede entenderse como una dimensión siempre presente en la vida de Israel y coexistente con la sacrificial, con diferentes acentos en cada momento.

Seguidamente nos centraremos en el análisis de la expiación en el siervo de Yahveh del Deuteroisaías, concretamente en el cuarto cántico del siervo (Is 52,13-53,12), ya que en este pasaje se parece aludir a una nueva forma de entender el sacrificio expiatorio, en esta línea de espiritualización, intercesión y mediación que comentamos. La revelación del A. T. alcanza aquí una cima nueva: «Hasta entonces el dolor aparecía como un misterio incomprensible; ahora se le atribuye un valor salvífico. El sufrimiento y la muerte del siervo son presentados como la más

${ }^{64}$ Cf. Marx, 36ss.

${ }^{65}$ En opinión de Pietro Bovati, cuando Yahveh no acepta el don presentado no se debe a que quiera un culto espiritual, sino principalmente a que se ofrece el don pretendiendo mantener una situación de injusticia. Dios no ama tanto la ofrenda en sí, como su significado: el corazón contrito y humillado. Cf. Bovati, 179-181.

${ }_{66}$ También en el pensamiento judío de la misma época. La expiación se realizaba por medio de la oración, el ayuno, las limosnas, la conversión, el respeto de la ley, etc. Cf. Maass. "Expiar", 1171.

${ }^{67}$ Cf. Marx, 39ss. 
extraordinaria intervención de Dios salvador» ${ }^{68}$. Además, se trata de un texto que tuvo una influencia notable en los autores neotestamentarios y a la luz del cual interpretaron la figura de Jesucristo.

\subsection{El CUARTO CANTO DEL SIERVO}

Mientras que los tres primeros cantos del siervo del Deuteroisaías tratan sobre la salvación que Dios quiere llevar a cabo a través de su siervo para todas las naciones, el cuarto canto «muestra cómo se realizará este propósito: a través del sufrimiento vicario del siervo por toda la humanidad» ${ }^{69}$.

Aunque se trata de un texto complejo, tanto respecto a la fijación del texto hebreo como en lo referente a su interpretación, la delimitación del cuarto canto del siervo no es motivo de discusión: Is 52,13-53,12. La estructura que propone Childs, en la que coinciden muchos exegetas, es la siguiente ${ }^{70}$ :

- 52,13-15: primer discurso de Dios.

- 53,1-11a: confesión del «nosotros».

- 53,11b-12: segundo discurso divino.

El personaje del siervo permanece en silencio durante todo el canto ${ }^{71}$. En la primera y en la última parte habla Yahveh, que anuncia el triunfo y la exaltación del siervo. En la parte intermedia un grupo (Israel) toma la palabra y muestra su desagrado y rechazo hacia el siervo por estar carente de belleza (signo, para ellos, de carencia de bendición divina) ${ }^{72}$.

68 Juan Alfaro. "Las funciones salvíficas de Cristo como revelador, Señor y sacerdote". En Mysterium Salutis: Manual de teología como historia de la salvación, dirigido por Johannes Feiner y Magnus Löhrer. Vol. 3, T. 1, 671-755, aquí 690. Madrid: Ediciones Cristiandad, 1971.

69 Alberto Ricciardi. "Los cantos del siervo de Yavé". Cuadernos de teología 4, n. ${ }^{\circ}$ (1976): 124-128, aquí 124.

${ }^{70}$ Cf. Brevard S. Childs. Isaiah. Louisville: Westminster John Knox Press, 2001, 411.

${ }^{71}$ Hay discusión entre los exegetas sobre si el siervo se refiere a una colectividad (y en ese caso a cuál) o a una persona individual. Véase una buena defensa de esta última opción en Médebielle, 203-216. Sea como fuere, la salvación conseguida por el siervo (uno) alcanza a los que se abren a ella (muchos), de manera que todo el que la acoja pertenece al mismo pueblo (cf. esta idea de solidaridad en Sal 22,32).

72 Cf. Claus Westermann. Isaiah 40-66. Philadelphia: The Westminster Press, 1969, 261. 
No obstante, hay un punto de inflexión en su percepción del siervo (no se sabe bien qué lo motiva) que lleva al «nosotros» a reconocer su culpa y sus faltas, soportadas por aquél en lugar de ellos. El canto muestra que ese «cargar sobre sí el pecado ajeno» es lo que consigue la salvación para todos ${ }^{73}$.

\section{6. ¿ES LA MEDIACIÓN DEL SIERVO UN SACRIFICIO EXPIATORIO?}

«El contenido es clarísimo, y por eso es tan extraño. Un inocente que debe sufrir (contra la doctrina de la retribución), mientras son respetados unos culpables (escándalo de algunos salmos); un humillado que triunfa (esto es menos extraño, aunque siempre sorprende), un muerto que vive (esto suena a ilusión poética). El poema es así [...] se trata de algo inaudito. [...] por tanto, no hay que reducirlo y nivelarlo con otros casos, aunque se puedan citar antecedentes y semejanzas» ${ }^{74}$.

Como advierten Schökel y Sicre, hay tal novedad en este poema que no se puede pretender reducirlo a comprensiones ajenas a él. No obstante, podemos profundizar en la idea de expiación a la que parece apuntar el canto e intentar relacionarla, salvando siempre las distancias, con la expiación según la entendía $\mathrm{P}$.

Si bien todo el poema en su conjunto sugiere la idea de un sacrificio personal del siervo que asume vicariamente los pecados de los otros, el versículo 10 nombra de manera bastante explícita la realidad que estamos estudiando: «si entrega su vida como expiación » ${ }^{75}$; «si se da a sí mismo en expiación ${ }^{76}$; «si haces de su vida un sacrificio expiatorio» ${ }^{77}$. El término empleado para «sacrificio de expiación» es 'as̄ham, que, como vimos,

${ }^{73}$ En un estudio monográfico, Paba Nidhani de Andrado defiende la existencia de un nexo soteriológico entre la Akedah o sacrificio de Isaac de Gn 22 y el cuarto cántico del siervo de Is 53. El esquema que acabamos de señalar para este último presenta numerosas similitudes con Gn 22, y ambos textos fueron determinantes para la comprensión de la expiación del N. T. Cf. Paba Nidhani de Andrado. The Akedah Servant Complex: The Soteriological Linkage of Genesis 22 and Isaiah 53 in Ancient Jewish and Early Christian Writings. Leuven: Peeters, 2013.

${ }^{74}$ Luis Alonso Schökel y José Luis Sicre. Profetas. Madrid: Cristiandad, 1980, 328-329.

75 Traducción de Schökel y Sicre en ibid.

76 Traducción de la Biblia de Jerusalén. 4. ${ }^{a}$ ed. Bilbao: Desclée de Brouwer, 2009.

77 Traducción de F. Cantera y M. Iglesias. Sagrada Biblia. Madrid: BAC, 2009. 
corresponde a los sacrificios de reparación por el pecado. Es el único caso en que aparece en Isaías ${ }^{78}$.

Aunque este versículo presenta muchas dificultades exegéticas, parece claro que el siervo se ofrece a soportar el sufrimiento que conlleva cargar con el mal ajeno para la salvación de otros. Así, aunque el plan surge de Dios (quien «carga» al siervo con estos sufrimientos), el siervo acepta libremente ser mediador e intercesor por los transgresores a través de su vida, su sufrimiento y su muerte ${ }^{79}$.

En opinión de Marta García, la salvación tiene lugar a través de un intercambio de bien y de mal: el siervo asume las culpas de los pecadores y consigue para ellos la paz y la curación ${ }^{80}$. Se trata de una manera paradójica de conseguir la salvación, precisamente a través de aquello que parece más lejano a ella. Dicho de otro modo, busca el éxito a través del fracaso.

La autora no es partidaria de interpretar esta transferencia de bien y de mal como una sustitución, puesto que se anularía la responsabilidad del transgresor. Por eso señala que, a su parecer, «el procedimiento que mejor respeta e integra la libertad humana, esencial al evento intercesorio, es el $r \hat{\imath} b{ }^{81}$.

${ }^{78}$ Cf. Schökel y Sicre, 334. Como vemos, no estamos ante la raíz kipper, propiamente el término técnico para "expiación», sino ante 'as̄ham, que hace referencia a un tipo de sacrificio expiatorio: el de reparación por el pecado. No obstante, la conexión con la expiación a través del sacrificio es obvia.

79 En este punto coinciden Marta García Fernández. "Consolad, consolad a mi pueblo": El tema de la consolación en Deuteroisaías. Roma: Gregorian \& Biblical Press, 2010, 259-262; Childs. Isaiah, 418; Westermann, 269; Hernando Barrios Tao. "Teología del sacrificio en Is 52,13-53,12: siervo nuevo, elección nueva, misión nueva, 'ofrenda' nueva”. Theologica Xaveriana 63, n. 175 (2013): 29-56 (40); Hermann Spieckermann. "The Conception and Prehistory of the Idea of Vicarious Suffering in the Old Testament". En The Suffering Servant. Isaiah 53 in Jewish and Christian Sources, editado por Bernd Janowski y Peter Stuhlmacher, 1-15. Michigan: Eerdmans, 2004; Bernd Janowski. "He Bore Our Sins: Isaiah 53 and the Drama of Taking Another's Place”. En The Suffering Servant, o. c., 48-74.

80 Cf. García Fernández, 251.

81 Ibid., 285. En el rîb la parte ofendida es la que tiene la iniciativa para la reconciliación, quien pone en marcha el proceso. Esta parte, además de asumir la acusación, puede ser al mismo tiempo intercesora por el culpable, ya que no quiere su destrucción, sino su conversión. Para ello el culpable tiene que darse cuenta de lo que ha hecho, reconocerlo, arrepentirse y estar dispuesto a hacer lo necesario para restaurar la relación. Si el acusado acoge esta oferta, el acusador es un intercesor, incluso un defensor. Si no la acoge, el acusador sigue siendo acusador, porque la otra parte no habrá accedido a la mediación. En ningún momento se desculpabiliza al agresor, ya 
La parte dañada u ofendida, Dios, es quien toma la iniciativa para restablecer su relación con los pecadores, y lo hace a través de su siervo, que ejerce la función antropológica o mediadora de la salvación. Su sufrimiento, por una parte, delata el mal que han hecho los culpables y lo pone ante ellos para que se den cuenta, pero también, por otra parte, se solidariza con ellos cargando con las consecuencias de su pecado, intercediendo así por ellos.

Ahora bien, los pecadores mantienen su libertad y su responsabilidad. De ellos depende acoger la salvación que emana de la intercesión del siervo reconociendo su culpa y estando dispuestos a cambiar. "De este modo, se deja la decisión última de su propia salvación a la libertad del pecador. Y esta intercesión se seguirá actuando en aquel que reconozca y confiese la función mediadora del siervo» ${ }^{82}$.

Este modo de obrar la salvación por parte de Dios no significa que estemos ante un Dios airado, sino que quiere la destrucción del pecado al ser asumido por el siervo para alcanzar la libertad del pueblo ${ }^{83}$. Lo que se busca, en suma, es la restauración de la alianza. Ésta se logra porque se consigue la confesión de la culpa por parte de Israel que lo capacita para acoger el perdón.

Aunque esta interpretación de la entrega del siervo de Yahveh desde la perspectiva del rîb es esclarecedora, cabría preguntarse si necesariamente deja fuera la comprensión de dicha entrega como sustitución por los pecadores, como apunta García. Dicho de otra forma: ¿anula siempre la sustitución la libertad de aquél a quien se sustituye? Depende, en nuestra opinión, de lo que se entienda por «sustitución».

Bernd Janowski interpreta que la entrega del siervo limpia la culpa de los pecadores porque él se pone en su lugar ${ }^{84}$. Estaríamos hablando, por tanto, de una sustitución, pero entendida de tal manera que no elimina la libertad de los sustituidos ${ }^{85}$. No se trata, para Janowski, de si la culpa

que su responsabilidad permanece. Sin embargo, a pesar de que siempre está presente el elemento de denuncia, lo que se busca con el rîb es restablecer la relación.

82 Ibid., 287.

83 En la misma línea se pronuncia Hermann Spieckermann, quien subraya la comunión de voluntades entre el siervo y Dios y el objetivo salvífico de su sufrimiento vicario; cf. Spieckermann. "Conception and Prehistory", especialmente 5ss.

${ }^{84}$ Cf. Janowski. "He Bore Our Sins".

${ }^{85}$ Médebielle también interpreta la entrega del siervo como sustitutoria por los pecadores, pero la comprende desde una perspectiva más legalista. No obstante, 
es o no transferible, sino de que alguien (en este caso, el siervo) ayude a quien ha caído bajo el poder del pecado a liberarse de él:

«El principio de que la violencia engendra violencia se agota a sí mismo en este que está incondicionalmente listo para la paz; conduce entonces ad absurdum. Esta es una realidad que no resulta racionalmente comprensible, pero aun así existe. Sin embargo, este proceder es también liberador, porque no se deja simplemente así como está: gracias a él, el "nosotros" reconoce su propia culpa. Los culpables reconocen que son culpables: ese es el principio del cambio. Pero nadie es capaz de reconocer esto por sí mismo. Semejante reconocimiento requiere un impulso "desde fuera" para hacer práctico el conocimiento teórico. Isaías 53 describe también esto» ${ }^{86}$.

En suma, para Janowski el carácter sustitutorio del siervo deriva de que toma sobre sí las consecuencias de las acciones de los pecadores para liberarlos de ellas y permitirles una reconciliación que, por sí solos, no son capaces de lograr. En realidad, esta comprensión no está tan lejos de la de Marta García al interpretar el canto desde el paradigma del rîb, sólo que en ambos casos se entiende la sustitución de maneras diferentes.

Desde nuestro punto de vista, interpretar el cuarto canto del siervo de Yahveh como un rîb no nos lleva a descartar directamente una lectura expiatoria del mismo. Según hemos estudiado, para P la expiación es, ante todo, un don de Dios que requiere también del arrepentimiento y la confesión del fiel. El esquema subyacente, por tanto, es el mismo en ambos casos.

La novedad estriba en la mediación del siervo, que difiere de la mediación sacerdotal de $\mathrm{P}^{87}$, puesto que no es sólo quien realiza el sacrificio, sino que también es la víctima que se ofrece para cargar sobre sí los pecados del pueblo (¿podría tener relación con el macho cabrío del día de la expiación que se lleva el pecado del pueblo al desierto?). En opinión de Barrios Tao, el simbolismo ritual pasa a ser realidad en la vida del siervo ${ }^{88}$.

también subraya la libertad del siervo a la hora de acoger esta misión. Cf. Médebielle, 224-235.

86 Janowski. "He Bore Our Sins", 72ss.

87 No obstante, a juicio de S. Lyonnet, la actividad del siervo está emparentada con la del Sumo Sacerdote porque se trata de una intercesión. Cf. Lyonnet. "Expiation et intercession”, 892.

${ }^{88}$ Barrios Tao. "Teología del sacrificio", 50. 
A nuestro juicio, las diferentes metáforas, ya sea el rîb (metáfora legal) o el sacrificio expiatorio (metáfora cultual), no son incompatibles, sino que sirven para expresar la novedad que supone la intercesión del siervo en continuidad con la tradición judía.

Además, en el análisis de la expiación no cultual en el Pentateuco aludimos a un tipo de pecados (graves o injustos, según Sklar) que no se expiaban a través de los sacrificios, sino gracias a la intercesión de un mediador entre el pueblo y Dios. ¿No responde la mediación del siervo del Deuteroisaías a este esquema?

En suma, la intercesión del siervo de Yahveh podría ser considerada un sacrificio expiatorio puesto que, por medio de él, Dios eliminaría el mal de los pecadores (si éstos consienten a ello a través del arrepentimiento y la acogida del perdón) sin destruirlos.

\section{CONCLUSIONES}

Como se ha podido percibir, resulta difícil dar una definición exacta de lo que el Antiguo Testamento entendía por «expiación». Tanto el texto bíblico como sus estudiosos hacen referencia a todo lo que rodea a la expiación (causas, consecuencias, mediadores, etc.), pero no a lo que la constituye como tal. De hecho, se suele aludir a ella a través de metáforas e interrelacionarla con otros términos, formando así campos semánticos que nos permitan acercarnos a esta realidad difícil de definir.

De nuestro estudio previo podemos extraer varias conclusiones que pueden facilitar la tarea de reconstruir lo más precisamente posible el significado de la expiación:

1. En primer lugar, Dios es el sujeto que efectúa la expiación y lo hace por amor a su pueblo. Los sacrificios rituales son un medio que él pone a disposición de Israel para obtener la expiación por los pecados, no una manera por la que el ser humano pueda realizar por sí mismo la expiación ${ }^{89}$. Esta característica es constante en todos los textos y está clara para la mayoría de los exegetas.

89 Por tanto, la interpretación que hace René Girard sobre el sacrificio expiatorio y su relación con la violencia (cf. Lénoir, 45-47) no es aplicable a la experiencia veterotestamentaria, en la que priman el amor y el deseo de reconciliación y no la necesidad de regular la violencia. 
2. La expiación tiene como objetivo restaurar el orden que se había dañado, tanto en las relaciones (reconciliación) como en el sistema de normas de pureza que regulaban el acceso a lo sagrado (purificación). Especialmente cuando se refiere a objetos o lugares, puede significar también una consagración a Yahveh.

3. Para dicha restauración se requiere detener o eliminar el mal, que parece ser el principal efecto de la expiación. Esto también implica hacerse cargo de las consecuencias del mal ${ }^{90}$.

4. Aunque la expiación es un don divino, se requiere una cierta disposición y un esfuerzo por parte del que la necesita. Este esfuerzo suele incluir siempre un reconocimiento del pecado, un deseo de ser liberado de él y el ofrecimiento a Dios de un don que simbolice la vida ${ }^{91}$.

5. La expiación es un acontecimiento tanto personal como comunitario.

6. Siempre (o casi siempre) hay una figura mediadora entre el pecador y Dios. En la expiación sacrificial, se trata del sacerdote. En otros casos, sobre todo en los que se comete un pecado de especial gravedad, existen otras figuras mediadoras (principalmente, los justos) que interceden por los pecadores. El siervo del Deuteroisaías es un caso único, porque, además, carga con las consecuencias del mal para favorecer la reconciliación de los pecadores con Dios.

En síntesis, podemos definir la expiación como la eliminación del mal que es necesaria para que los procesos de restauración y de reconciliación lleguen a buen puerto. Sólo Yahveh es capaz de tal eliminación, pero es necesaria la participación del creyente (por lo menos reconociendo su pecado y acogiendo los beneficios de la expiación). Éste, a su vez, puede precisar la intervención de un mediador o intercesor humano. Como puede apreciarse, el Antiguo Testamento entiende la expiación como un proceso relacional. François Bourassa resume bien este cruce de libertades en la obra expiatoria:

${ }^{90}$ Cf. Emilio J. Justo. La salvación: Esbozo de soteriología. Salamanca: Sígueme, 2017, 106.

${ }_{91}$ Como vimos, el uso antiguo del término kốfcer, precio de rescate o compensación, parece subrayar esta vertiente de la expiación. No obstante, no es el uso predominante. 
«[...] si el término kipper significa en principio la acción de Dios que perdona, que restaura los pecados, [y] la acción litúrgica del sacerdote que hace la expiación por los pecados, no solamente este término en su origen significa igualmente la acción del pecador que ofrece compensación (kopher) por su falta, sino que el favor de Dios en consideración a su pueblo y la plenitud de su perdón (kipper) consiste en que él ofrece al hombre poder borrar su pecado delante de él, "redimirse" a sí mismo o redimir su falta, y entrar así verdaderamente en su amistad ${ }^{92}$.

Menos claro resulta determinar en qué consiste exactamente la eliminación del mal, es decir, cómo actúa la expiación: ¿borra el mal?93 ¿Lo oculta? ¿Lo extirpa de raíz? ¿Neutraliza sus consecuencias? Hay quien señala que, para el Antiguo Testamento, la expiación rompe la conexión entre el pecado y la desgracia que se deriva del mismo ${ }^{94}$, pero ya hemos visto que en los casos de pecado grave la expiación tiene lugar, mientras que se mantiene algún tipo de castigo (es decir, de consecuencias objetivas).

El siervo del Deuteroisaías introduce un elemento nuevo: la eliminación del mal se lleva a cabo por la asunción o la carga de éste (o, más bien, de sus consecuencias) por parte del inocente para la salvación de los culpables. Al tratarse en este tipo de mediación de una iniciativa divina con la que el siervo colabora humanamente, podríamos decir que en él se da una unión entre el dinamismo descendente de la expiación y el dinamismo ascendente, ambos presentes también en la expiación cultual.

Esta unidad será perfectamente encarnada por Jesucristo, verdadero Dios y verdadero hombre. El Nuevo Testamento, que bebe de la concepción veterotestamentaria de la expiación, realiza una concentración cristológica de la misma: en la persona de Jesucristo confluyen el amor divino que se ofrece para expiar el pecado, la figura del sacerdote del A. T., la víctima ofrecida para el sacrificio y el justo que carga con el sufrimiento ajeno para interceder por los pecadores.

92 Bourassa. "Expiation”, 159.

93 El texto de Lv 10,17 parece apuntar en esta dirección: "[comer la víctima del sacrificio por el pecado] era cosa sacratísima que se os daba a vosotros para borrar la falta de la comunidad, haciendo expiación por ellos ante Yahvé».

94 Por ejemplo, cf. von Rad, 341. 


\section{REFERENCIAS}

Alfaro, Juan. "Las funciones salvíficas de Cristo como revelador, Señor y sacerdote". En Mysterium Salutis: Manual de teología como historia de la salvación, dirigido por J. Feiner y M. Löhrer. Vol. III, Tomo I, 671755. Madrid: Ediciones Cristiandad, 1971.

Alonso Schökel, Luis y José Luis Sicre. Profetas. Vol. I. Madrid: Cristiandad, 1980.

Alsup, John E. "Expiation”. En The HarperCollins Bible Dictionary (ed. revisada), editado por Paul J. Achtemeier, 319-320. San Francisco: HarperSanFrancisco, 1996.

Andrado, Paba Nidhani de. The Akedah Servant Complex: The Soteriological Linkage of Genesis 22 and Isaiah 53 in Ancient Jewish and Early Christian Writings. Leuven: Peeters, 2013.

Angulo Ordorika, Ianire. “Tu pueblo será mi pueblo y tu Dios será mi Dios' (Rut 1,16). El libro de Rut: creer en tiempos inciertos". Proyección LXV (2018): 267-290.

Barrios Tao, Hernando. "Teología del sacrificio en Is 52,13-53,12: siervo nuevo, elección nueva, misión nueva, 'ofrenda' nueva”. Theologica Xaveriana 63 , n. ${ }^{\circ} 175$ (2013): 29-56.

Bourassa, François. "Expiation”. Science et Esprit 22, n. ${ }^{\circ}$ (1970): 149-170.

Bovati, P. Ristabilire la giustizia. Roma: Editrice Pontificio Istituto Biblico, 1986.

Briley, Terry. "The Old Testament 'Sin Offering' and Christ's Atonement". Stone-Campbell Journal 3 (2000): 89-101.

Brümmer, Vincent. Atonement, Christology and the Trinity: Making Sense of Christian Doctrine. Aldershot: Ashgate, 2005.

Childs, Brevard S. Teología bíblica del Antiguo y del Nuevo Testamento. Salamanca: Sígueme, 2011.

Childs, Brevard S. Isaiah. Louisville: Westminster John Knox Press, 2001.

Eichrodt, Walther. Teología del Antiguo Testamento. Vol. I, Dios y pueblo. Madrid: Cristiandad, 1975.

Festugière, A.-J. "AN $\Theta^{\text {' }} \Omega \mathrm{N}$. La formule 'en échange de quoi' dans la prière grecque hellénistique". Revue des Sciences philosophiques et théologiques 60 (1976): 389-418.

García Fernández, Marta. "Consolad, consolad a mi pueblo": El tema de la consolación en Deuteroisaías. Roma: Gregorian \& Biblical Press, 2010. García López, Félix. El Pentateuco. Estella: Verbo Divino, 2002. 
Hayes, John H. “Atonement in the Book of Leviticus”. Interpretation 52 (1998): 5-15. DOI: https://doi.org/10.1177\%2F002096439605200102 Jacob, Edmond. Teología del Antiguo Testamento. Madrid: Marova, 1969. Janowski, Bernd. "He Bore Our Sins: Isaiah 53 and the Drama of Taking Another's Place”. En The Suffering Servant. Isaiah 53 in Jewish and Christian Sources, dirigido por B. Janowski y P. Stuhlmacher, 48-74. Michigan: Eerdmans, 2004.

Justo, Emilio J. "El estatuto epistemológico de la soteriología”. Scripta Theologica 50, n. ${ }^{\circ} 2$ (2018): 303-319. DOI: https://doi. org/10.15581/006.50.2.303-319

Justo, Emilio J. La salvación: Esbozo de soteriología. Salamanca: Sígueme, 2017.

Kibbe, Michael. "Is it finished? When did it start? Hebrews, priesthood, and atonement in biblical, systematic, and historical perspective". The Journal of Theological Studies 65 (2014): 25-61. DOI: https://doi. org/10.1093/jts/flu016

Lénoir, Frédéric. Breve tratado de historia de las religiones. Barcelona: Herder, 2018.

Link, H.-G. y H. Vorländer. “Reconciliación (ì $\lambda \varepsilon \omega \varsigma)$ ). En Diccionario teológico del Nuevo Testamento, dirigido por Lothar Coenen, Erich Beyreuther y Hans Bietenhard. Vol. 4, 36-48. Salamanca: Sígueme, 1984.

Lyonnet, Stanislas. “The Terminology of 'Expiation' in the Old Testament”. En Sin, Redemption, and Sacrifice: A Biblical and Patristic Study, Stanislas Lyonnet y Léopold Sabourin, 120-136. Rome: Biblical Institute Press, 1970.

Lyonnet, Stanislas. “The Terminology of 'Expiation' in the Septuagint”. En Sin, Redemption, and Sacrifice: A Biblical and Patristic Study, Stanislas Lyonnet y Léopold Sabourin, 137ss. Rome: Biblical Institute Press, 1970.

Lyonnet, Stanislas. "Expiation et intercession. Note complémentaire: le témoignage des anciennes versions latines”. Biblica 41, n. 2 (1960): 158-167.

Lyonnet, Stanislas. "Expiation et intercession. A propos d'une traduction de saint Jerôme”. Biblica 40, n. 3 (1959): 885-901.

Maass, F. "Expiar”. En Diccionario teológico manual del Antiguo Testamento, dirigido por Ernst Jenni y Claus Westermann. Vol. 1, 1152-1171. Madrid: Cristiandad, 1978. 
Marx, Alfred. Los sacrificios del Antiguo Testamento. Cuadernos bíblicos 111. Estella: Verbo Divino, 2002.

Maxwell Whyte, H. A. El poder de la sangre. New Kensington: Whitaker House, 2010.

McEwan, Ian. Expiación. Barcelona: Anagrama, 2002.

Médebielle, Alexis. L'expiation dans l'Ancien et le Nouveau Testament. Rome: Institut Biblique Pontifical, 1923.

Milgrom, Jacob. Leviticus 1-16. A new translation with introduction and commentary. Vol. 1. New York: Doubleday, 1991.

Moraldi, Louis. "Expiation". En Dictionnaire de Spiritualité. Ascétique et Mystique. Doctrine et Histoire, dirigido por M. Viller, F. Cavallera y J. de Guibert. Tomo 4. 2026-2045. Paris: Beauchesne, 1960.

Preuss, Horst Dietrich. Teología del Antiguo Testamento. Vol. II, El camino de Israel con Yahvé. Bilbao: Desclée de Brouwer, 1999.

Rad, Gerhard von. Teología del Antiguo Testamento. Vol. I, Las tradiciones

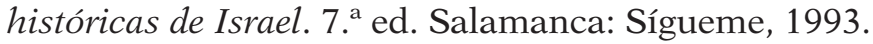

Ricciardi, Alberto. "Los cantos del siervo de Yavé". Cuadernos de teología 4, n. 2 (1976): 124-128.

Ruiz de la Peña, Juan Luis. La pascua de la creación: Escatología. 2. ${ }^{a}$ ed. Madrid: BAC, 2000; 4. ${ }^{\text {a }}$ reimpr., 2011.

Schenker, Adrian. "Expiación”. En Diccionario Crítico de Teología, dirigido por Jean-Yves Lacoste, 482-484. Madrid: Akal, 2007.

Sklar, Jay. "Sin and Atonement: Lessons from the Pentateuch". Bulletin for Biblical Research 22 (2012): 467-491.

Spieckermann, H. "The Conception and Prehistory of the Idea of Vicarious Suffering in the Old Testament". En The Suffering Servant. Isaiah 53 in Jewish and Christian Sources, dirigido por B. Janowski y P. Stuhlmacher, 1-15. Michigan: Eerdmans, 2004.

Westermann, Claus. Isaiah 40-66. Philadelphia: The Westminster Press, 1969. 